\title{
Variations in growth and virulence of Leptographium wingfieldii Morelet, a fungus associated with the bark beetle Tomicus piniperda L.
}

\author{
François LIEUTIER ${ }^{\mathrm{a}, \mathrm{b} *}$, Annie YART ${ }^{\mathrm{b}}$, Hui YE $^{\mathrm{c}}$, Daniel SAUVARD $^{\mathrm{b}}$, Valérie GALlOIS $^{\mathrm{b}}$ \\ ${ }^{a}$ Laboratoire de Biologie des Ligneux et des Grandes Cultures, Université d'Orléans, BP 6749, 45067, Orléans, France \\ b Unité de Zoologie Forestière, INRA, avenue de la Pomme de Pin, BP 20619 Ardon, 45166 Olivet Cedex, France \\ ${ }^{\mathrm{c}}$ Institute of Ecology and Geobotany, Yunnan University, Kunming 650091, P.R. China
}

(Received 18 December 2001; accepted 17 January 2003)

\begin{abstract}
Growth and virulence of various isolates of Leptographium wingfieldii Morelet, isolated from Tomicus piniperda L. and galleries initiated by this insect on Scots pine (Pinus sylvestris L.) at different parts of the forest of Orléans, were compared. Six isolates were tested in 1994 and 15 in 1995. The tested parameters included the growth on malt agar at different temperatures, the ability of the fungus to stimulate the hypersensitive reaction in the phloem and to grow into the reaction zone after isolated inoculations of Scots pine trees, as well as fungal virulence to Scots pine after mass inoculations. Significant differences between isolates were observed for all parameters. These differences mainly refer to gradual variations among isolates, even though some isolates were constantly opposed to each other for all or most parameters. No obvious effect of the locality, from where the isolates had been obtained, was detected. The results suggest that the population of $L$. wingfieldii in the forest of Orléans consists of isolates that possess a high individual variability in growth characteristics and virulence to their host tree. Fungal growth both on malt agar and in the phloem was positively correlated with the length of the reaction zone in the phloem after isolated inoculations and with parameters related to fungal virulence after mass inoculations. Likewise, length of the reaction zone in the phloem was positively correlated to the number of killed trees and the percentage of blue stained sapwood area after mass inoculations. The results are discussed in relation to the possible origin of the variability in fungal growth and virulence, and to practical use of fungal growth on malt agar and in the phloem for screening and comparing the virulence of various isolates within the same blue stain fungal species.
\end{abstract}

Leptographium wingfieldii / Tomicus piniperda / intraspecific variability / growth / virulence / tree defense reaction / temperature / Orléans

Résumé - Variabilité de la croissance et de la virulence de Leptographium wingfieldii Morelet, champignon associé au Scolyte Tomicus piniperda L. La croissance et la virulence de divers isolats de Leptographium wingfieldii Morelet, isolés d'adultes de Tomicus piniperda L. et de leurs galeries provenant d'attaques récentes sur des pins sylvestres (Pinus sylvestris L.) dans différentes zones de la forêt d'Orléans, ont été comparées. Six isolats ont été considérés en 1994 et 15 en 1995. Les paramètres testés étaient la vitesse de croissance sur malt agar à diverses températures, la capacité du champignon à stimuler la réaction hypersensible du liber et à croître dans la zone de réaction après inoculations ponctuelles à des pins sylvestres, et sa virulence après inoculations massives sur Pin sylvestre. Des différences significatives entre isolats ont été observées pour tous les paramètres. Elles correspondent essentiellement à des variations graduelles, même si certains isolats étaient constamment opposés les uns aux autres pour tous ou la plupart des paramètres. Aucun effet évident de la localité d'origine des isolats n'a été détecté. Les résultats suggèrent que la population de L. wingfieldii de la forêt d'Orléans est composée d'isolats possédant une variabilité individuelle élevée en ce qui concerne les caractères de croissance et la virulence pour l'hôte. La croissance sur malt agar et dans le liber était corrélée positivement avec la longueur de la zone de réaction hypersensible dans ce tissu après inoculation ponctuelle, et avec les paramètres de la virulence des isolats après inoculations massives. De même, la longueur de la zone de réaction dans le liber était positivement corrélée avec le nombre d'arbres tués et le pourcentage d'aubier bleui après inoculations massives. Les résultats sont discutés eu égard à l'origine possible de la variabilité de la croissance et de la virulence, et à la possibilité d'utiliser la croissance sur malt agar et dans le liber pour trier et comparer la virulence de divers isolats de la même espèce.

Leptographium wingfieldii / Tomicus piniperda / variabilité intraspécifique / croissance / virulence / réaction de défense / température / Orléans

\footnotetext{
* Corresponding author: francois.lieutier@univ-orleans.fr
} 


\section{INTRODUCTION}

Bark beetle associated blue stain fungi are thought to play an important role in beetle establishment on their conifer hosts by contributing to exhaust the host resistance [4, 14, 24, 25]. The basic mechanism of conifer defense against bark beetles is the development of a hypersensitive response in the phloem and the sapwood, mainly consisting of an enrichment of secondary metabolites in the tissues of the tree around each site of attack [1, 3, 26, 29, among others]. This tree reaction against bark beetle attack is induced by the mechanical stress due to the tunneling activity of the insect and can be considerably amplified by the fungi introduced by the beetle into the wound $[14,20]$. The level of resistance of an individual tree is defined as the critical threshold of attack density above which its defense mechanisms are overcome $[2,4,25$, 40]. By stimulating the tree hypersensitive reaction, the fungi accelerate the energy expenditure of the tree, thus lowering the critical threshold and consequently helping the beetle population to establish on its host. In addition, after contributing to exhaust the resistance of the tree and allowing the success of attacks, the fungi can also contribute to kill the tree by invading and occluding the sapwood $[14,24]$. Artificial mass inoculations of bark beetle associated blue stain fungi are often used to mimic mass attacks by bark beetles and to define a critical threshold of inoculation density for individual bark beetle / blue stain fungus / host systems $[5,7,9,38]$. This method is especially useful for comparison of the resistance level of trees with varying vigor levels or to compare the pathogenicity of different fungi. Generally, there is no or only a weak relationship between the critical threshold of inoculation density of associated fungi and bark beetle aggressiveness [24] or the critical threshold of attack density of bark beetles during natural infestations [14]. This results from the fact that often only a minor proportion of the beetles in a population vectors pathogenic fungi $[17,24,33]$, and that the mode of inoculation of fungi by spores introduced by a beetle into the tree greatly differs from artificial inoculation which is usually done with mycelium or very high numbers of spores obtained from fungal cultures $[14,16]$.

The pine shoot beetle Tomicus piniperda L. (Coleoptera: Scolytidae) is an economically important pest of various pine species in Europe. It is associated with Leptographium wingfieldii Morelet [22] at a constant, but very low level of infestation, since only $5 \%$ of the attacking beetles carry the fungus $[17,37]$. Leptographium wingfieldii does not seem to play an ecological role, for its vector, comparable to that described above, because it does not stimulate the tree hypersensitive response when it is naturally introduced by the beetle into the tree, possibly due to too low a number of introduced spores $[13,20]$. However, it has a very good ability to stimulate the tree response after artificial inoculation [16, 18, 37], which makes it an excellent test organism to study the defense mechanisms of pine. It displays a high level of virulence since it is able to kill healthy Scots pine trees at a low (about 400/m²) density of artificial inoculation within a $1-\mathrm{m}$ wide inoculation belt $[5,38]$. It has been suggested to play a possible role in killing trees after attacks by $T$. piniperda have succeeded $[13,14]$.

The mycobiota associated with a given bark beetle species can show considerable variations between localities and years and may be related to bark beetle population levels $[8,24]$. Likewise growth and pathogenicity of associated fungi vary between different species [8, 18, 19, 30, 31, 34, 35, 38]. Comparisons of pathogenicity between different fungal species, even associated with the same insect vector, have been commonly performed. For the fungi associated with Tomicus spp., it has been reported that fast growing species (L. wingfieldii, O. minus) were pathogenic to Scots pine, while a slow growing fungal associate (O. canum) was not [36]. Much less results refer to intra-specific variations. Regarding the fungi associated with $T$. piniperda, the virulence of different isolates of L. wingfieldii, originating from various localities in Sweden and France, has been reported to vary after low density inoculations [21]. In Ceratocystis polonica (Siem.) C. Moreau (a fungus associated with Ips typographus L. on Picea abies [L.] Karst.), different cultures from the same isolate differed in their growth and virulence, and a relationship between these two parameters was established [12]. In this case, however, differences in performance between cultures were thought to be caused by several years of cultivations on malt agar in the laboratory. To our knowledge, nothing has been published regarding the possibility that fungal growth and virulence vary from one isolate to another in the same forest.

In the present paper, we explore the intra-specific variability between isolates obtained from the same forest. We report on two experiments aiming at investigating the variations in growth and virulence of $L$. wingfieldii in the Scots pine forest of Orléans, France. Together with its insect vector, this fungus is widespread in the forest of Orléans.

\section{MATERIALS AND METHODS}

The forest of Orléans ( $35000 \mathrm{ha}, 127 \mathrm{~m}$ above sea level) is located on the Northern rim of the Loire river and extends from North-West to South-East, along a roughly decreasing gradient of soil quality (Fig. 1). Although the forest is all of a piece, 4 main geographic entities can be distinguished from West to East, the massif of Orléans (6 $500 \mathrm{ha})$, the massif of Ingrannes (13 $500 \mathrm{ha})$, and the Northwestern (6 000 ha) and Southeastern (9 000 ha) massifs of Lorris. Each entity is separated from the others by a narrow but still forested area. For historical and management reasons, the whole forest is divided into many plots consisting on an average of about 25 ha and being separated from each others by straight and more or less wide alleys or paths. Soils are essentially sands and clay, with sands increasing from northwest to southeast. The water table is everywhere close to the soil surface in winter, thus preventing the roots from extending deeply into the soil, but can descend considerably in spring and summer, causing sometimes extensive water stress. The original forest type consists of oak (Quercus robur L. and Q. petraea [Mattuschka] Liebl.), birch (Betula pendula Roth and B. alba L.) and hornbeam (Carpinus betulus L.) but pines, essentially Scots pine (Pinus sylvestris L.), have been planted extensively since the beginning of the 19th century, especially on bad soils. As a result, Scots pine covers presently about half of the total forested area, the proportion of pine plots increasing from West to East to reach very high values in the southeastern massif of Lorris, but large plots of pines also exist in the massif of Orléans. Plots consist often of monocultures of one species, but many others comprise mixed species stands. The forest of Orléans is isolated from other forests. The closest pine woodlands are about $15 \mathrm{~km}$ south on the opposite rim of the Loire river.

The experiments were carried out in spring 1994 and 1995. In FebruaryMarch, T. piniperda and galleries initiated by this bark beetle were 


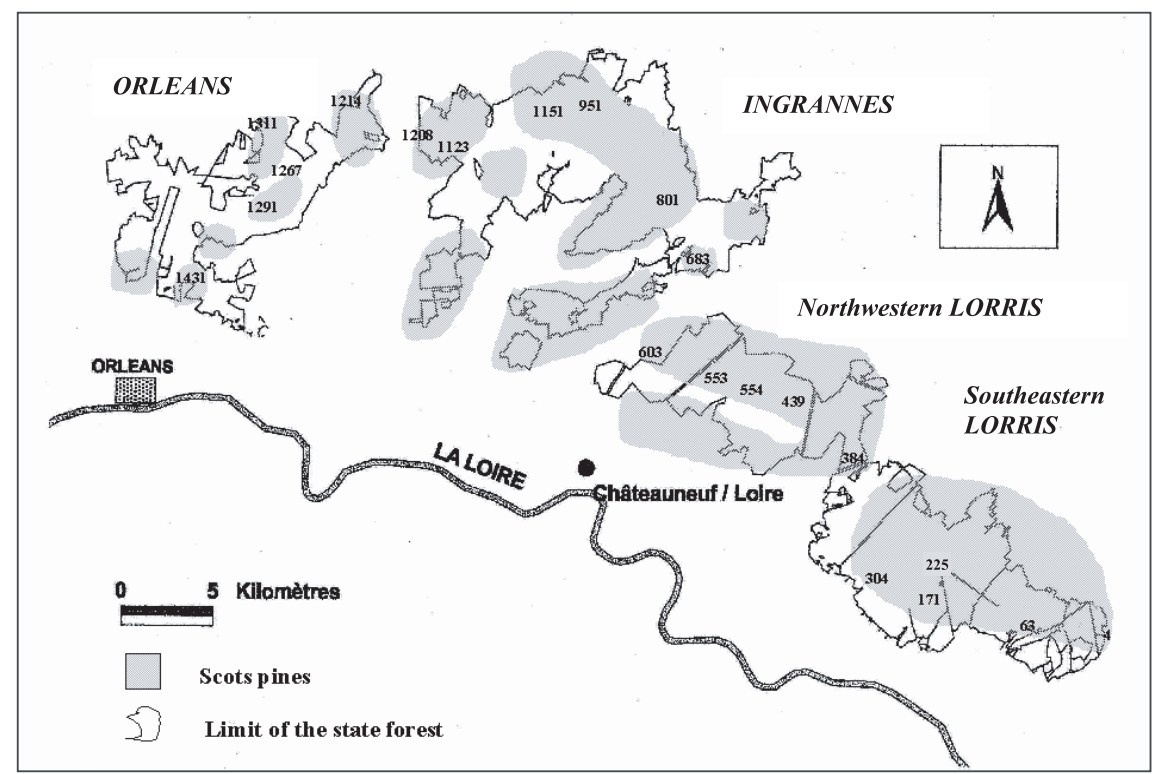

Figure 1. Map of the forest of Orléans, with limits of the state forests, the 4 massifs and the zones of pine forests. The numbers of the plots from where the isolates were originating are indicated.

collected from freshly attacked logs of Scots pine at various plots of the forest. L. wingfieldii was isolated from these samples on malt agar medium (3\% malt extract, $1.6 \%$ agar) and the isolates were purified. Single conidial cultures were prepared from each isolate. Six isolates were kept in 1994 and 15 in 1995. Each year, they originated from plots distributed throughout the different parts of the forest (Fig. 1). The isolates were designated by the respective plot numbers they had been originating from. The purified isolates were compared for their growth on malt agar medium, their ability to stimulate the tree hypersensitive reaction in the phloem of the tree and to grow into the reaction zone in the phloem after artificial inoculations at low density, as well as their virulence after artificial mass inoculations.

In 1994, the growth of the 6 isolates was tested at 3, 10, 15, 20, 25 and $30{ }^{\circ} \mathrm{C}$ in the dark. At day 0 , a 5 -mm diameter agar plug from a 2-week-old culture was placed in the center of a 9-cm diameter Petri dish containing $20 \mathrm{ml}$ of malt agar (VWR International) medium (3\% malt, $1.6 \%$ agar). At each temperature, 8 replicates were used for each isolate, and the growth was recorded each day during 5 days by the measurement of 2 orthogonal diameters from which the diameter of the agar plug was subtracted. In 1995, growth of the 15 isolates was tested at $25^{\circ} \mathrm{C}$ in the dark. Eight replicates per isolate were used and diameters of the fungal colonies were measured after 3 days as described above.

Inoculations at low density were performed in March 1994 and June 1995. In both years, each of ten 30 -year-old Scots pine trees (15 to $20 \mathrm{~cm}$ diameter), located in the Northwestern massif of Lorris received 2 inoculations per isolate. At each inoculation point, a 5-mm diameter plug of bark and phloem was removed with a cork borer, and a 5-mm diameter disk from a 2-week-old malt agar culture was inserted into the wound, with the mycelium side directed towards the sapwood. The bark plug was then replaced to maintain the mycelium and to avoid desiccation of inoculum. In 1994, the inoculations were located in 2 rings per tree at 1.00 and $1.50 \mathrm{~m}$ above ground. Within each ring, the inoculations were dispersed at equal intervals. Each ring contained one replicate of each isolate and the 2 replicates of a same isolate were located on opposite sides of the tree. Ten days later, the outer bark was removed around each inoculation point of the top ring and length of the reaction zone was measured on the external surface of the phloem. The reaction zone in the phloem was then sampled and the fungus extension was quantified in the laboratory by reisolations at $5 \mathrm{~mm}$ intervals along the reaction zone above and below the inoculation point. Twenty one days after inoculation, the same measurements were made on the inoculations of the bottom ring. In 1995 , the 2 series of replicates were each composed of 2 rings, the rings being located $30 \mathrm{~cm}$ apart from each other between $70 \mathrm{~cm}$ and $160 \mathrm{~cm}$ above ground and the 2 replicates of a same isolate being on opposite sides of the tree. The same measurements as in 1994 were done, all 14 days after inoculation.

Mass inoculations were performed in April 1994 on 6-to-8-cm diameter and 15-year-old trees, and in July 1995 on 6-to-12-cm diameter and 17-year-old trees, in the Northwestern massif of Lorris. The inoculation technique was the same as described above and the density was $400 / \mathrm{m}^{2}$ within a $1-\mathrm{m}$ wide belt beginning at $70 \mathrm{~cm}$ above ground. Three trees per isolate were used in 1994 and 5 trees in 1995. 100 days after mass inoculation, tree survival was determined according to foliage color by considering that only the trees with a dark green foliage were surviving, while those with a light green or a yellow to red foliage were going to die or were already dead. After foliage assessment, all trees were harvested and 3 thin cross-sectioned disks were taken from each bole, one in the middle and two at a distance of $25 \mathrm{~cm}$ below the upper end, respectively above the lower end of the inoculation zone. The surface areas of resinous, desiccated, blue stained and healthy sapwood sections on each disk were delineated on transparent paper and then quantified by weighing the corresponding paper areas. Percentages of blue stained sapwood area and healthy sapwood area were computed. Each tree was characterized by the average values of its 3 disks.

For the percentage of killed trees, only the extreme values from each experiment were subjected to statistical analyses ( $\mathrm{Chi}^{2}$ test). Thus, trees inoculated with isolates that killed none or one tree were taken together, and were compared to the group of trees inoculated with isolates that killed 3 or 4 trees. For the other data, each isolate was characterized by the average values obtained from each tree in which it had been inoculated. After verification of the normality of 


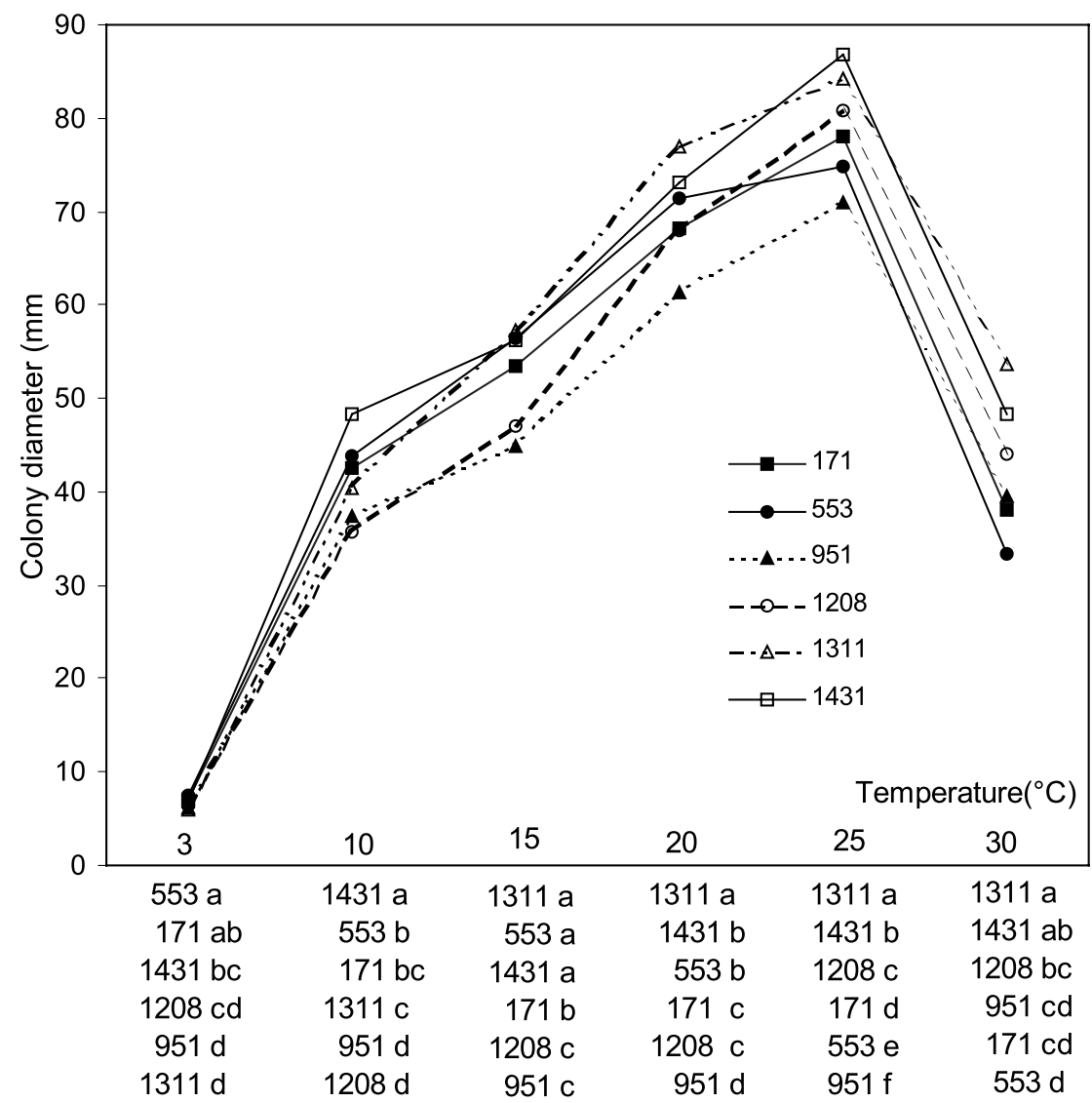

Figure 2. Colony diameter of different isolates of $L$. wingfieldii on malt agar 5 days after incubation at different temperatures (experiment 1994). For a given temperature, isolates with the same letter have colony diameters which do not differ significantly.

the data, comparisons between means were performed by ANOVA (GLM procedures), followed by Tukey tests. Pearson and Spearman correlations were calculated at the isolate level (6 replicates in 1994; 15 in 1995), except for correlations among different sapwood parameters and for correlations between sapwood parameters and tree diameter. In those cases, calculations were done at the tree level (18 replicates in 1994; 75 in 1995). Correlations and differences between means were considered as significant at the $5 \%$ level. All statistics were performed with S.A.S. software [27].

\section{RESULTS}

\subsection{Fungal growth on malt agar}

All isolates collected in 1994 had a growth optimum around $25{ }^{\circ} \mathrm{C}$. Growth was very slow at $3{ }^{\circ} \mathrm{C}$, then increasing gradually from 10 to $25^{\circ} \mathrm{C}$, but decreasing dramatically at $30{ }^{\circ} \mathrm{C}$ (Fig. 2). However, there were obvious and statistically significant differences in growth - temperature relationships and growth rate between the six isolates. Interestingly, isolates with the fastest growth at the lowest temperature (\# 553 and 171) grew slowest at the highest temperature and the opposite was observed for isolate \# 1311. This suggests that isolates differ considerably in their temperature preferences. There were important and statistically significant differences in growth at $25^{\circ} \mathrm{C}$ between isolates collected in 1995 (Fig. 3).

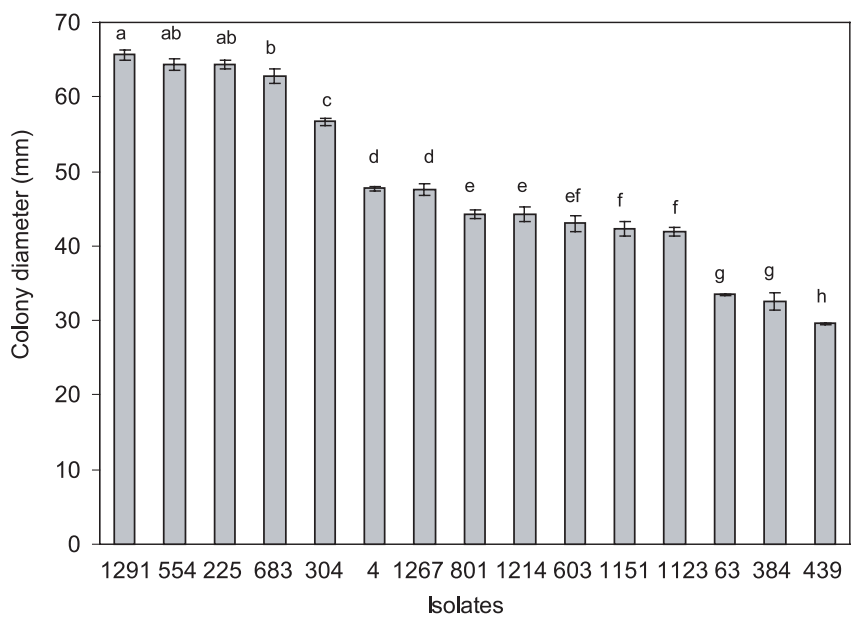

Figure 3. Colony diameter of different isolates of $L$. wingfieldii on malt agar 3 days after incubation at $25^{\circ} \mathrm{C}$ (experiment 1995). Vertical bars represent the standard errors. Values with the same letter do not differ significantly.

Isolates 1291, 554, 225 and 683 displayed the fastest growth, and isolates 63, 384 and 439 grew slowest. Comparison of growth values of isolates originating from different massifs did not reveal any locality effect. 


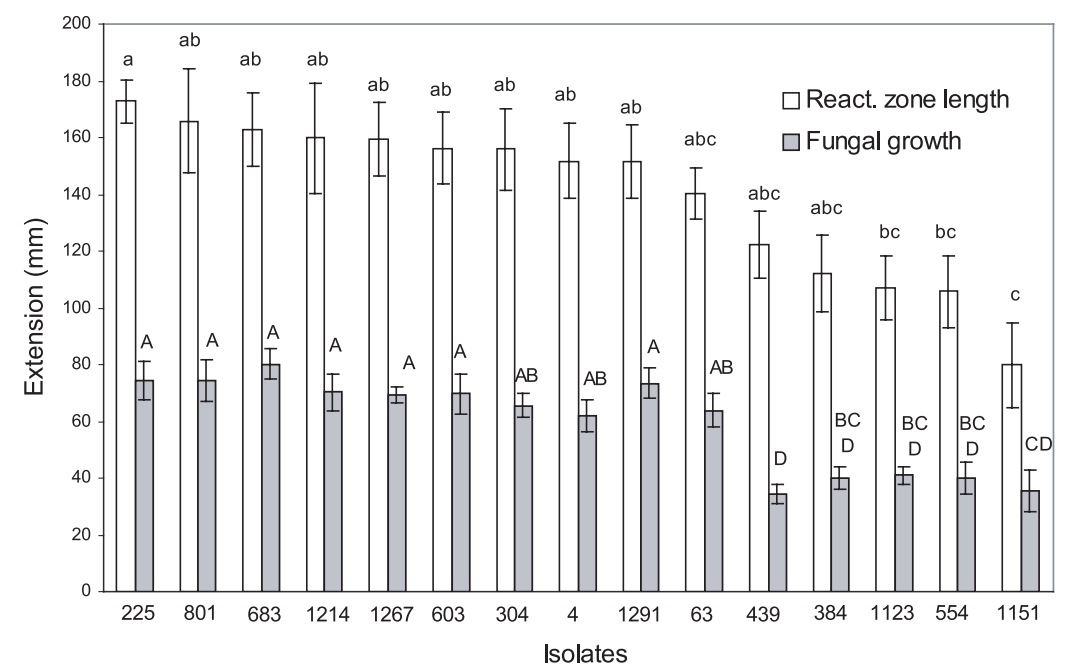

Figure 4. Length of the reaction zone in the phloem and fungal growth within the reaction zone, 14 days after inoculation of Scots pine trees with various isolates of L. wingfieldii (experiment 1995). Vertical bars represent the standard errors. For a given variable, values with the same letter do not differ significantly.

Table I. Number of killed test trees, assessed by their foliage color, 100 days after mass inoculations. The total number of test trees per isolate was 3 in 1994 and 5 in 1995. Groups of isolates with different letters differed significantly from each other (Chi ${ }^{2}$ test; within these groups, each tree was considered as one replicate, regardless of the isolate used).

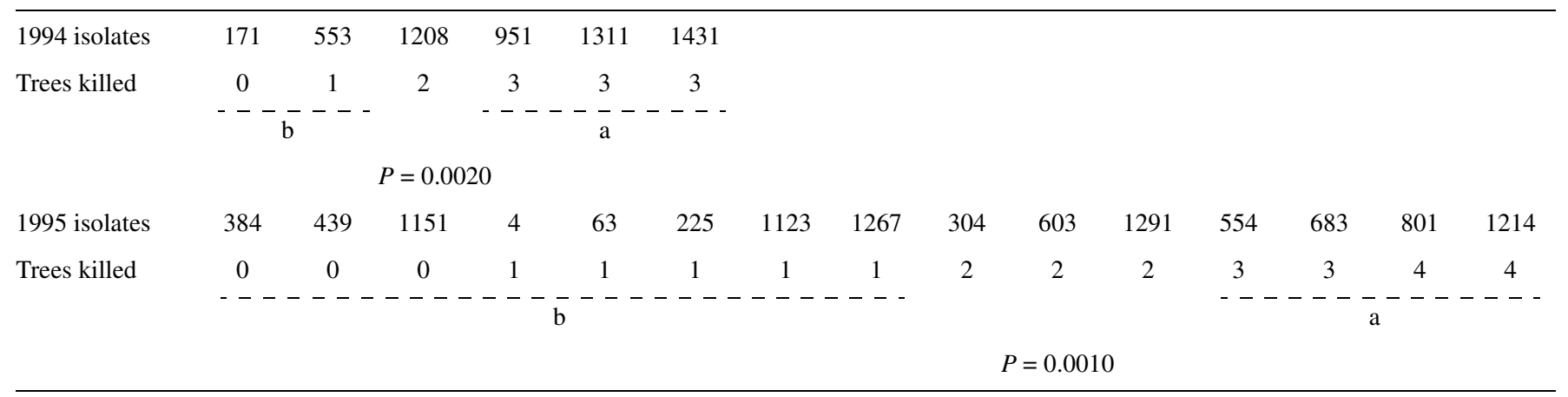

\subsection{Ability to stimulate the hypersensitive reaction in the phloem and to grow into the reaction zone}

In 1994, both 10 and 21 days after inoculation, no significant differences were found between isolates, neither regarding the length of the phloem reaction zone in the phloem nor fungal growth inside that zone (data not shown). The overall average values of reaction zone length and fungal growth inside necrotic lesions were $10.4 \pm 1.4 \mathrm{~cm}$ (mean \pm standard error) and $4.9 \pm 0.6 \mathrm{~cm}$, respectively, 10 days after inoculation, and $18.0 \pm 1.3 \mathrm{~cm}$ and $6.5 \pm 0.9 \mathrm{~cm}$ at day 21 . However, at day 10, isolate 1431 tended to grow further than all other isolates except isolate $951(P=0.0511)$ (data not shown). In 1995, 14 days after inoculation, highly significant differences were found between isolates $(P=0.0001)$, both for the length of the reaction zone in the phloem and fungal growth inside the reaction zone (Fig. 4). These differences were mainly gradual. In terms of fungal growth, however, isolates 439, 384, 1123, 554 and 1151, with their low growth, formed a group separated from all other isolates except 304, 4 and 63. Regarding reaction zone length, the separation of these two groups is less clear but the same tendency exists. No locality effect could be detected by comparing isolates originating from different massifs.

\subsection{Fungal virulence after mass inoculation}

Depending on the isolates, the number of trees killed or going to be killed by the mass inoculation, assessed by foliage color, varied from 0 to 3 in 1994 and from 0 to 4 in 1995 (Tab. I). In both experiments, the number of killed trees in the group with the least virulent isolates $(171+553$ in 1994; $4+$ $63+225+384+439+1123+1151+1267$ in 1995) differed significantly from that in the group with the most virulent isolates $(951+1311+1431$ in $1994 ; 554+683+801+1214$ in 1995). In the experiment in 1995, a comparison of the trees that were surviving the mass inoculation with those that were killed or going to be killed, regardless of fungal isolate, revealed that the former ones had a significantly lower diameter $(83.40 \pm 3.50 \mathrm{~mm})$ than the latter ones $(91.68 \pm 4.77 \mathrm{~mm})$ $(P=0.0066)$, while the average diameter of the inoculated trees did not differ between isolates $(P=0.9996)$.

After averaging the values from the three disks of each tree, the percentage of blue stained sapwood 100 days after mass inoculations never differed between isolates $(P=0.0859$ in 1994; $P=0.0839$ in 1995), although isolate 171 in 1994 and isolates 1151, 384 and 439 in 1995 caused no blue stain while other isolates (1431, 951 and 1311 in 1994; 683 and 1214 in 1995) caused up to $53 \%$ blue stain (Fig. 5). The percentage of 
Table II. Correlations between parameters, calculated either at the isolate level (6 replicates in 1994; 15 in 1995) or at the tree level (18 replicates in 1994; 75 in 1995). The number of replicates is indicated under the correlation coefficient. Only significant correlations are presented; they are indicated with * (level 5\%) and ** (level 1\%). Pearson (p) or Spearman (s) correlations are presented, depending whether correlations are linear or not. $\%$ Kill = percentage of trees killed or going to be killed; $\%$ Blue = percentage of blue stained sapwood area; $\%$ Health $=$ percentage of healthy sapwood area; Diam = tree diameter; RZL = reaction zone length; FGRZ = fungal growth in the reaction zone; FGMA = fungal growth on malt agar medium at $25^{\circ} \mathrm{C}$.

\begin{tabular}{|c|c|c|c|c|c|c|c|c|}
\hline & \multicolumn{2}{|c|}{$\%$ Blue } & \multicolumn{2}{|c|}{$\%$ Health } & \multirow{2}{*}{$\begin{array}{l}\text { Diam } \\
1995\end{array}$} & \multirow{2}{*}{$\begin{array}{l}\text { RZL } \\
1995\end{array}$} & \multirow{2}{*}{$\begin{array}{c}\text { FGRZ } \\
1995\end{array}$} & \multirow{2}{*}{$\begin{array}{r}\text { FGMA } \\
1995\end{array}$} \\
\hline & 1994 & 1995 & 1994 & 1995 & & & & \\
\hline \multirow[t]{2}{*}{$\%$ Kill } & 0.98 & 0.87 & -0.94 & -0.87 & & 0.52 & 0.70 & 0.55 \\
\hline & $\mathrm{p}^{* * 6}$ & $\mathrm{~s}^{* * 15}$ & $\mathrm{~s}^{* * 6}$ & $\mathrm{p} * * 15$ & & $\mathrm{~s}^{*} 15$ & $\mathrm{~s}^{* *} 15$ & $\mathrm{~s} * 15$ \\
\hline \multirow[t]{2}{*}{$\%$ Blue } & & & -0.94 & -0.89 & 0.29 & 0.81 & 0.9 & 0.60 \\
\hline & & & $\mathrm{s} * * 18$ & s**75 & $\mathrm{s} * 75$ & $\mathrm{~s} * * 15$ & $\mathrm{~s} * * 15$ & $\mathrm{~s} * 15$ \\
\hline \multirow[t]{2}{*}{$\%$ Health } & & & & & -0.35 & -0.58 & -0.70 & -0.60 \\
\hline & & & & & $\mathrm{p}^{* * 75}$ & $\mathrm{p}^{*} 15$ & $\mathrm{p}^{* * 15}$ & $\mathrm{p}^{*} 15$ \\
\hline \multicolumn{9}{|l|}{ Diam } \\
\hline \multirow[t]{2}{*}{ RZL } & & & & & & & 0.93 & \\
\hline & & & & & & & $\mathrm{p}^{* *} 15$ & \\
\hline \multirow[t]{2}{*}{ FGRZ } & & & & & & & & 0.59 \\
\hline & & & & & & & & $\mathrm{s} * 15$ \\
\hline
\end{tabular}
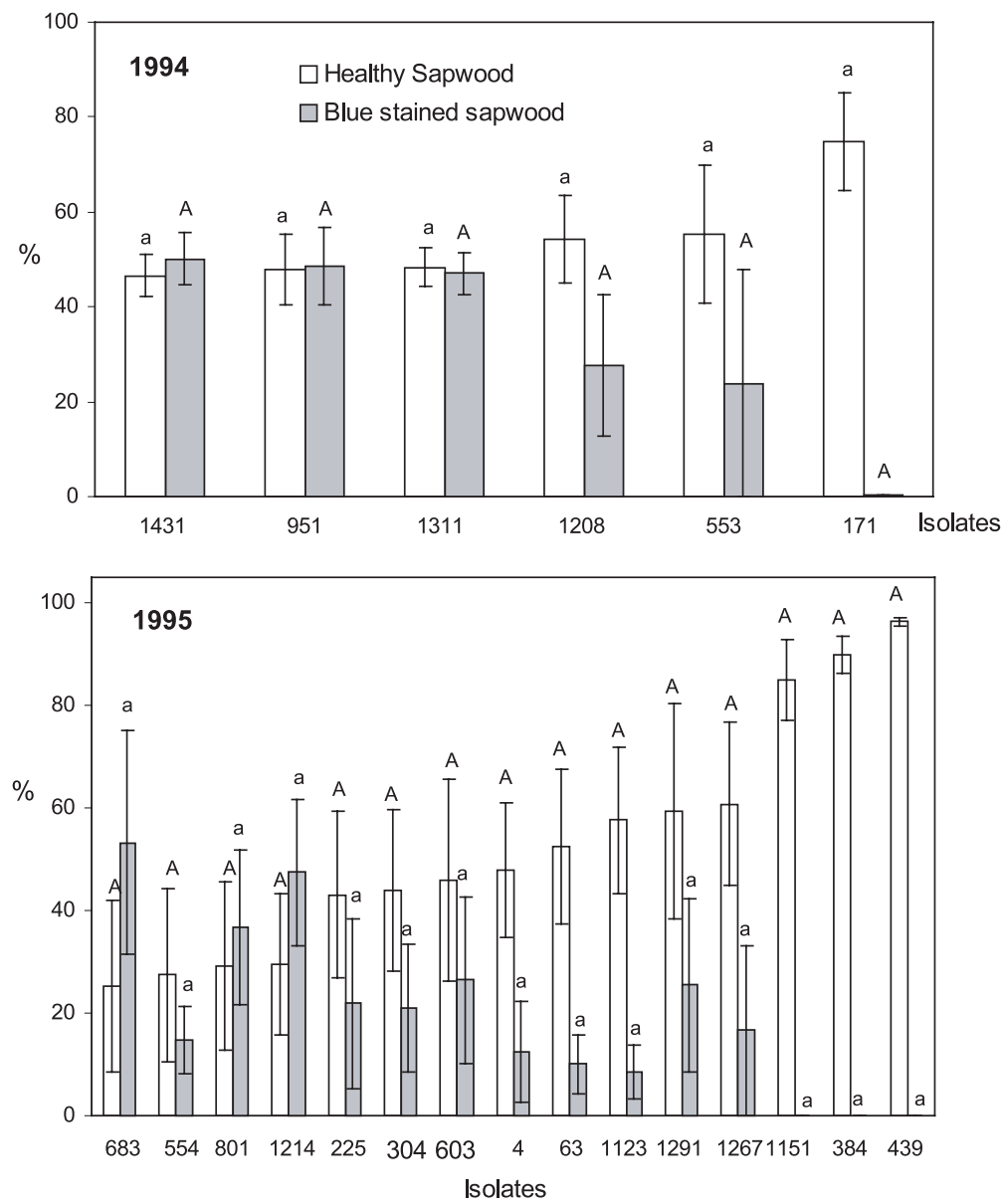

Figure 5. Percentages of blue stained and healthy sapwood, 100 days after mass inoculation of Scots pine trees with different isolates of $L$. wingfieldii, collected and tested in 1994 and 1995. Values represent the averages of three stem disks for each tree. Vertical bars represent the standard errors. For a given variable, values with the same letter do not differ significantly. 
healthy sapwood did not depend on the isolate in 1994 $(P=0.3018)$, but a very significant isolate effect was found in 1995 ( $P=0.0119$ ) (Fig. 5). However, even in 1995, the Tukey test did not separate individual isolates from each others, although the percentage of healthy sapwood in trees that had been inoculated with isolates 683, 554, 801 and 1214 varied between 25 and 30, while that of test trees inoculated with isolates 1151,384 and 439 was equal to or higher than 85 . No consistent effect of origin of isolates from the various localities on sapwood parameters was detected.

\subsection{Correlations between parameters}

The percentage of trees killed by the isolates after mass inoculations was always highly and positively correlated with the percentage of blue stained sapwood and negatively with the percentage of healthy sapwood, the two latter parameters being also highly and negatively correlated to each other (Tab. II). Tree diameter was weakly positively correlated to the percentage of blue stained sapwood and negatively to the percentage of healthy sapwood. Fungal growth within the reaction zone in the phloem after low density inoculations was highly and positively correlated to the length of the reaction zone. It was also positively correlated to fungal growth on malt agar medium. These 3 parameters were all positively correlated to the parameters related to tree death after mass inoculation and negatively to that related to tree survival.

\section{INTERPRETATION AND DISCUSSION}

\subsection{Variations in growth and virulence between isolates of $L$. wingfieldii}

The present paper clearly shows that there is a significant variability in growth and virulence among various isolates of L. wingfieldii collected in the forest of Orléans. Due to the low number of isolates and tree replicates, the differences in virulence among isolates were not significant in 1994, but the tendency was the same as in the experiment in 1995 which gave statistically significant results. Variability between isolates refers to all the studied parameters: fungal growth both on malt agar medium and in the phloem, the ability to stimulate the defense reaction in the phloem after single inoculations, as well as the virulence after mass inoculation, either assessed by the foliage color, the percentage of blue stained sapwood or the percentage of healthy sapwood.

Isolates of $L$. wingfieldii have a growth optimum around $25^{\circ} \mathrm{C}$ and all of them can grow slowly at $3{ }^{\circ} \mathrm{C}$. This is in agreement with previously published results $[15,36]$ and confirms the adaptation of $L$. wingfieldii to relatively low temperatures and thus to a beetle which starts to swarm very early in the season. The temperature-growth relationship, however, seemed to vary between isolates, and significant differences in growth on malt agar between isolates were observed. The increase in fungal growth in the phloem between day 10 and day 21 after single inoculations in 1994, is also in full agreement with the comprehensive, previously published results on the growth of various bark beetle - associated fungi, including $L$. wingfieldii, from day 3 to day 60 after single inoculations [18].
The differences in growth and virulence have, for each of the parameters tested, resulted in the recognition of extreme groups of isolates. However, few isolates were consistently opposed to each other for all parameters. Only isolates 384, 439 and 1151, with a much slower growth both on malt agar and in the phloem, much shorter reaction zones in the phloem, and much less virulence after mass inoculation were constantly opposed to isolate 683 which was always among the best isolates for all parameters. Isolate 554 was close to 683 and opposed to the three other ones with low performance, for all parameters except virulence after single inoculations. In most cases, however, there were gradual variations among isolates. Moreover, for each parameter tested, within a group of isolates with similar performances, different massifs were always represented, and no locality effect was demonstrated for any parameter. This suggests that isolates with varying levels of virulence and growth rate coexist everywhere in the forest, without any geographic separation and that, very likely, they coexist even on the same plots. The wide-spread occurrence of isolates with varying physiological characteristics throughout the forest can easily be explained by transportation of the fungus by a good flying insect. Indeed, T. piniperda can fly up to $4 \mathrm{~h} \mathrm{[6],} \mathrm{which} \mathrm{may} \mathrm{allow} \mathrm{dispersal} \mathrm{of} \mathrm{about} 30 \mathrm{~km}$ with classic bark beetle speed. In addition, it has a dispersion phase on a large scale during the period of its shoot feeding [28]. The slow growth rate and low levels of virulence of some isolates might be due to infections by mycoviruses, as already reported for Ophiostoma novo-ulmi and O. ulmi [39]. This possibility deserves further studies in the future.

Our results thus demonstrate, for the first time, that variability in growth and virulence can exist among a population of a bark beetle-associated fungus originating from a relatively small geographic area, i.e. the forest of Orléans. The ecological consequences of differences in virulence between isolates of fungi associated with bark beetle species are still very poorly known and deserve further study, especially regarding bark beetle population dynamics and establishment on trees.

\subsection{Relationship between parameters}

In this study, we found a very strong and highly significant correlation between fungal growth in the reaction zone in the phloem and the reaction zone length, in the case of punctual inoculations. This finding is not surprising since the fungus is responsible for stimulating the defense reaction of the tree. In addition, we found highly significant correlations between, reaction zone length and fungal growth after punctual inoculations on the one hand, and sapwood occlusion and tree mortality after mass inoculations on the other hand (Tab. II). These results indicate that the length of the reaction zone and fungal growth in the phloem after punctual inoculations could effectively be used to screen isolates for their virulence, at least when comparing strains belonging to the same species. When comparing different fungal species, only very weak correlations between reaction zone length after punctual inoculations and fungal pathogenicity after mass inoculations have often been detected, and several authors have thus concluded that it is difficult or even impossible to assess the virulence of different blue stain fungi based on results from isolated inoculations [11, 30, $34,38]$. The contrasting conclusions between the present and 
the former studies $[11,30,34,38]$ could be explained by differences in fungal behavior, being much larger between species than between isolates within the same species. In particular, while various blue stain fungal species mainly infect the phloem and show slower spread in the sapwood, the opposite has been reported for other species [32, 34, 35, 41].

We also found significant correlations between fungal growth on malt agar and growth in the reaction zone in the phloem and, consequently, between fungal growth on malt agar and virulence to pine trees after mass inoculations. Previous results have suggested such a relationship, mostly between species $[31,35,36]$. Such a relationship has also been detected in various cultures of $C$. polonica after several years of cultivation in the laboratory [12]. Our study demonstrates that the relationship between growth on malt agar and fungal virulence exists naturally in isolates belonging to the same species and originating from the same forest. This interesting result could be of great practical use for screening and comparing fungal virulence of various fungal isolates, at least in this particular blue stain fungus / host system.

Since the average size of the inoculated trees did not differ between treatments, the result that the trees killed by mass inoculation had a higher diameter than the surviving trees and that tree diameter was also slightly positively correlated to the percentage of blue stained sapwood, proves that the biggest trees were the least resistant ones to infection by $L$. wingfieldii after mass inoculations. This could be explained by assuming that the majority of the available resources in the fast growing trees are invested in growth rather than in defense [10]. However, it has often been reported that trees with the highest productivity indices are also the most resistant ones to attack by bark beetles and infection by associated blue stain fungi [23, 42].

Acknowledgments: The authors thank the Office National des Forêts, Management Center of Orléans, for allowing them to collect fungal isolates and to carry out the inoculation experiments in the forest. They are also grateful to Jacques Garcia and Paul Romary (INRA, Ardon) for their technical help. They thank two anonymous reviewers for their very constructive and helpful comments on a first version of the manuscript.

\section{REFERENCES}

[1] Berryman A.A., Resistance of conifers to invasion by bark beetle fungus associations, BioScience 22 (1972) 598-602.

[2] Berryman A.A., Theoretical explanation of mountain pine beetle dynamics in lodgepole pine forests, Environ. Entomol. 5 (1976) 1225-1233.

[3] Brignolas F., Lieutier F., Sauvard D., Yart A., Drouet A., Claudot A.-C., Changes in soluble phenol content of Norway spruce (Picea abies Karst.) phloem in response to wounding and inoculation with Ophiostoma polonicum, Eur. J. For. Pathol. 25 (1995) 253-265.

[4] Christiansen E., Waring R.H., Berryman A.A., Resistance of conifers to bark beetle attack: searching for general relationships, For. Ecol. Manage. 22 (1987) 89-106.

[5] Croisé L., Lieutier F., Dreyer E., Scots pine responses to number and density of inoculation points with Leptographium wingfieldii Morelet, a bark beetle-associated fungus, Ann. Sci. For. 55 (1998) 497-506.
[6] Forsse E., Migration in bark beetles with special reference to the spruce bark beetle Ips typographus, Thesis, Sveriges Lantbruksuniversitet, Uppsala, Sweden, 1989.

[7] Guérard N., Dreyer E., Lieutier F., Interactions between Scots pine, Ips acuminatus (Gyll.) and Ophiostoma brunneo-ciliatum (Math.): estimation of the critical thresholds of attack and inoculation densities and effects on hydraulic properties of the stem, Ann. For. Sci. 57 (2000) 681-690.

[8] Harding S., The Influence of Mutualistic Blue Stain Fungi on Bark Beetle Population Dynamics, Ph.D. thesis, Department of Zoology, Royal Veterinary and Agricultural University, Copenhagen, Denmark, 1989.

[9] Horntvedt R., Christiansen E., Solheim H., Wang S., Artificial inoculation with Ips typographus-associated blue-stain fungi can kill healthy Norway spruce trees, Medd. Nor. Inst. Skogforsk. 38 (1983) 1-20.

[10] Kozlowski T.T., Kramer P.J., Pallardy S.G., The Physiological Ecology of Woody Plants, Academic Press, Inc., New York, 1991.

[11] Krokene P., Solheim H., What do low-density inoculations with fungus tell us about fungal virulence and tree resistance? in: Lieutier F., Mattson W.J., Wagner M.R. (Eds.), Physiology and Genetics of Tree-Phytophage Interactions, Versailles, INRA Editions, 1999, pp. 353-362.

[12] Krokene P., Solheim H., Loss of virulence in the blue-stain fungus Ceratocystis polonica, Plant Pathol. 50 (2001) 497-502.

[13] Lieutier F., Associated Fungi, Induced Reaction and Attack Strategy of Tomicus Piniperda (Coleoptera: Scolytidae) in Scots Pine, in: Hain F.P., Salom S.M., Ravlin W.F., Payne T.L., Raffa K.F. (Eds.), Behavior, Population Dynamics and Control of Forest Insects, Proc. Intern. Union For. Res. Organizations Joint Conf., 1994 February 6-11, Maui, Hawaï, 1995, pp. 139-153.

[14] Lieutier F., Mechanisms of resistance in conifers and bark beetle attack strategies, in: Wagner M.R., Clancy K.M., Lieutier F., Paine T.D. (Eds.), Mechanisms and Deployment of Resistance in Trees to Insects, Kluwer Academic, Dordrecht, 2002, pp. 31-77.

[15] Lieutier F., Yart A., Preferenda thermiques des champignons associés à Ips sexdentatus Boern. et Tomicus piniperda L. (Coleoptera: Scolytidae), Ann. Sci. For. 46 (1989) 411-415.

[16] Lieutier F., Cheniclet C., Garcia J., Comparison of the defense reactions of Pinus pinaster and Pinus sylvestris to attacks by two bark beetles (Coleoptera: Scolytidae) and their associated fungi, Environ. Entomol. 18 (1989) 228-234.

[17] Lieutier F., Yart A., Garcia J., Ham M-C., Morelet M., Lévieux J., Champignons phytopathogènes associés à deux Coléoptères Scolytidae du Pin sylvestre (Pinus sylvestris L.) et étude préliminaire de leur agressivité envers l'hôte, Ann. Sci. For. 46 (1989) 201-216.

[18] Lieutier F., Yart A., Garcia J., Ham M-C., Cinétique de croissance des champignons associés à Ips sexdentatus Boern. et à Tomicus piniperda L. (Coleoptera: Scolytidae) et des réactions de défense des pins sylvestres (Pinus sylvestris L.) inoculés, Agronomie 10 (1990) 243-256.

[19] Lieutier F., Garcia J., Yart A., Vouland G., Pettinetti M., Morelet M., Ophiostomatales (Ascomycètes) associées à Ips acuminatus Gyll (Coleoptera: Scolytidae) sur le Pin sylvestre (Pinus sylvestris L.) dans le Sud-Est de la France et comparaison avec Ips sexdentatus Boern., Agronomie 11 (1991) 807-817.

[20] Lieutier F., Garcia J., Romary P., Yart A., Wound reactions of Scots pine (Pinus sylvestris L.) to attacks by Tomicus piniperda L. and Ips sexdentatus Boern. (Coleoptera: Scolytidae), J. Appl. Entomol. 119 (1995) 591-600.

[21] Lieutier F., Langström B., Solheim H., Hellqvist C., Yart A., Genetic and Phenotypic Variation in the Induced Reaction of Scots Pine Pinus Sylvestris L., to Leptographium Wingfieldii: Reaction Zone Length and Fungal Growth, in: Mattson W.J., Niemela P., Rousi M. (Eds.), Dynamics of Forest Herbivory: Quest for Pattern and Principle, USDA For. Serv. Gen. Tech. Rep. NC-183, 1996, pp. 166-177.

[22] Morelet M., Observations sur trois Deuteromycètes inféodés aux pins, Ann. Sci. Nat. Arch. de Toulon et du Var 40 (1988) 41-45.

[23] Mulock P., Christiansen E., The threshold of successful attack by Ips typographus on Picea abies: a field experiment, For. Ecol. Manage. 14 (1986) 125-132. 
[24] Paine T.D., Raffa K.F., Harrington T.C., Interactions among scolytids bark beetles, their associated fungi, and live host conifers, Annu. Rev. Entomol. 42 (1997) 179-206.

[25] Raffa K.F., Berryman A.A., The role of host plant resistance in the colonization behavior and ecology of bark beetles (Coleoptera: Scolytidae), Ecol. Monogr. 53 (1983) 27-49.

[26] Reid R.W., Whitney H.S., Watson J.A., Reactions of lodgepole pine to attack by Dendroctonus ponderosae Hopkins and blue stain fungi, Can. J. Bot. 45 (1967) 115-126.

[27] SAS Institute Inc. 6.12, Cary, NC, USA, 1989-1996.

[28] Sauvard D., Lieutier F., Lévieux J., Distribution spatiale de Tomicus piniperda L. (Coleoptera: Scolytidae) en forêt d'Orléans, Ann. Sci. For. 44 (1987) 417-434.

[29] Shrimpton D.M., Extractives associated with wound response of lodgepole pine attacked by the mountain pine beetle and associated microorganisms, Can. J. Bot. 51 (1973) 527-534.

[30] Solheim H., Pathogenicity of some Ips typographus-associated blue stain fungi to Norway spruce, Medd. Nor. Inst. Skogforsk. 40 (1988) $1-11$.

[31] Solheim H., Oxygen deficiency and spruce resin inhibition of growth of blue stain fungi associated with Ips typographus, Mycol. Res. 95 (1991) 1387-1392.

[32] Solheim H., Fungal succession in sapwood of Norway spruce infested by the bark beetle Ips typographus, Eur. J. For. Pathol. 22 (1992) 136-148.

[33] Solheim H., Fungi associated with the spruce bark beetle Ips typographus in an endemic area in Norway, Scand. J. For. Res. 8 (1993) $118-122$.
[34] Solheim H., Krokene P., Growth and virulence of mountain pine beetle associated blue stain fungi, Ophiostoma clavigerum and Ophiostoma montium, Can. J. Bot. 76 (1998) 561-566.

[35] Solheim H., Krokene P., Growth and virulence of Ceratocystis rufipenni and three blue stain fungi isolated from the Douglas-fir beetle, Can. J. Bot. 76 (1998) 1763-1769.

[36] Solheim H., Krokene P., Långström B., Effects of growth and virulence of associated blue-stain fungi on host colonization behaviour of the pine shoot beetles Tomicus minor and T. piniperda, Plant Pathol. 50 (2001) 111-116.

[37] Solheim H., Långström B., Blue stain fungi associated with Tomicus piniperda in Sweden and preliminary observation on their pathogenicity, Ann. Sci. For. 48 (1991) 149-156.

[38] Solheim H., Långström B., Hellqvist C., Pathogenicity of the bluestain fungi Leptographium wingfieldii and Ophiostoma minus to Scots pine: effect of the tree pruning and inoculum density, Can. J. For. Res. 23 (1993) 1438-1443.

[39] Sutherland M.L., Brasier C.M., A comparison of thirteen d-factors as potential biological control of agents of Ophiostoma novo-ulmi, Plant Pathol. 46 (1997) 680-693.

[40] Thalenhorst W., Grundzüge der populationdynamik des großen Fichtenborkenkäfers Ips typographus L., Schrift. Forst. Fak. Univ. Göttingen 21 (1958) 1-126.

[41] Uzunovic A., Webber J.F., Comparison of bluestain fungi grown in vitro and in freshly cut pine billets, Eur. J. For. Pathol. 28 (1998) 323-334.

[42] Waring R.H., Pitman G.B., A simple model of host resistance to bark beetles, Oreg. State Univ. For. Res. Lab. Res. Note 65, 1980. 